\title{
Retinoic Acid Binding Proteins and Cancer: Similarity or Polarity?
}

\author{
Elena M Tchevkina* \\ Institute of Carcinogenesis, NN Blokhin National Medical Research Center of Oncology, Russia
}

Submission: November 24, 2017; Published: December 07, 2017

"Correspondence Address: Elena M Tchevkina, Institute of Carcinogenesis, NN Blokhin National Medical Research Center of Oncology, 155478, Moscow, Kashirskoye sh, 24, Moscow, Russia, Tel: +7 499-324-1764; Email: tchevkina@mail.ru

\begin{abstract}
Vitamin A is a precursor for the multiple active metabolites, known as retinoids, among which retinoic acid (RA) is one of the most essential for the embryonic development as well as for the tissue maintenance and renewal in adults. RA upregulates the transcription factors that control the expression of a huge number of genes regulating differentiation, proliferation, cellular death and survival. Potent anticarcinogenic activity of RA has been repeatedly shown for several types of cancer cells. However, the implementation of RA as a therapeutic agent for cancer treatment is limited by the rapid acquisition of RA resistance. Moreover, in some type of tumors RA promotes rather than inhibits cell malignancy. One of the reasons for the development of RA resistance and such distinct functional significance of RA in carcinogenesis is attributed to the proteins, responsible for the delivery of RA to its nuclear receptors regulating transcription and intracellular signaling. The association with the different kind of RA binding proteins largely determines the future fate of RA and its intracellular activity.
\end{abstract}

Keywords: Retinoic acid; RAR; CRABP-I; CRABP-II; FABP5

\section{Introduction}

Retinoic acid (RA) is one of the most active derivatives of vitamin A (retinol), belonging to the huge family of retinoids. RA is the first open morphogen in vertebrates and plays a huge role in embryonic development. In adults RA regulates multiple biological processes including tissue remodeling and regulation of the immune response. The intracellular functions of the RA are also associated primarily with stimulation of differentiation or apoptosis and with negative regulation of proliferation. Due to its pro-differentiation activity RA plays predominantly anti-oncogenic or tumor-suppressive role in the context of carcinogenesis. At present an active attempts are being made to use RA and its derivatives in the therapy of malignant neoplasms [1-5]. However, the use of PA is strongly restricted by the rapid acquisition of cell resistance, as well as by a large number of side effects $[5,6]$.

In addition, in some types of tissues (primarily in skin and in neuronal cells), RA plays an inverse function, stimulating cell survival and proliferation [7-11]. The reasons for such different functional significance of the RA, as well as the mechanisms of cell resistance to the RA, are not fully understood. The growing pool of evidences points to the key role in these processes of the group of proteins that bind PA in cytoplasm and largely determine its further fate as well as its effect on cells. At the same time, the data on the significance of each of these proteins are very contradictory. This review is an attempt to consider current knowledge on the multiple roles that RA-binding proteins play in mediating of the biological activities of retinoic acid, as well as to assess their significance for cancer progression.

\section{RA Nuclear Receptors}

The "canonical" activity of the RA is accomplished by regulating the activity of several hundred genes. This activity is mediated by nuclear receptors of RA, ligand-inducible transcription factors belonging to the super family of nuclear hormone receptors that regulate the expression of genes containing retinoid-responsive elements (RARE) in their promoter regions. The main receptors of the RA are RAR (RAR $\alpha, \beta$ and $\gamma$ ) and RXR proteins, which preferentially bind different isoforms of RA and are capable of forming heterodimers. Besides, RA binds the third nuclear receptor, $\operatorname{PPAR} \beta / \delta$, which functions, like RAR, in a heterodimer with RXR. Importantly, the repertoire of genes under RA control includes different groups of -RAR- and PPAR $\beta / \delta$-dependent ones.

\section{RA binding proteins.}

Intracellular transport of hydrophobic RA and its delivery to the different type of receptors is conducted by the members of lipid-binding proteins (iLBP) family: CRABP-I and CRABP-II 


\section{Cancer Therapy \& Oncology International Journal}

(cellular retinoic acid binding proteins-I and -II, delivering RA towards RARs) [12] and FABP5 (fatty acid binding protein 5, delivering RA towards PPAR $\beta / \delta$ ) [13]. It should be noted that the affinity of CRABP-RAR complex to RA is higher than that of FABP5-PPAR $\beta$ / $\delta$ complex [14]. That's the reason why in the majority of cells the action of the RA via RARs dominates, while activation of the FABP5 - PPAR $\beta$ / $\delta$ pathway occurs only in cells with a high FABP5 / CRABP ratio $[9,15,16]$ RARs are thought to activate transcription of genes that induce differentiation, apoptosis, or cell cycle arrest [17-21], while PPAR $\beta / \delta$ promotes expression of genes responsible for survival, proliferation, and angiogenesis [9,22-24]. Consequently, RA inhibits growth of tumors that express CRABP (more precisely, CRABP2, see below) but strengthens the oncogenic potential of carcinomas with high level of FABP5 expression [16,25].

In fact, there are 2 high-homologous (74\% homology) CRABP proteins: CRABP-II and CRABP-I, both bind RA to a similar extent (CRABP-I slightly better than CRABP-II) [12], but the significance of this binding seems fundamentally distinct. Binding of RA with CRABP-II protein causes conformational changes leading to the activation of the nuclear localization signal (NLS) and subsequent translocation of protein into the nucleus where CRABP-II interacts directly with RAR proteins. This interaction significantly facilitates the formation of the active complex of RA-RAR and enhances the transcriptional activity of RAR receptors. In accordance with this activity, the CRABP-II protein is commonly considered as tumor suppressor, and that is confirmed by a number of data [9,26-28]. At the same time there is also some evidence of tumor-promoting role of CRABP-II protein [29-31]. It is not excluded, however, that this role may not be related to its RA binding activity (see below).

The mechanisms of CRABP- I activity are much less understood. Despite that CRABP-I, like CRABP-II could be found in the nucleus [32], this protein does not interact directly with RARs. Accordingly, CRABP-I -mediated transfer of RA to its receptors requires first the dissociation of the RA-CRABP-I complex and the subsequent association of RA with RAR $[12,33]$. Therefore, even if CRABP-I is able to activate the RAR-dependent transcription, it does this less efficiently than CRABP-II. One of the possible functions of CRABP-I can be protection of cells from the excess of retinoic acid. In support of this hypothesis several studies show a reduction in the effects of RA in the presence of CRABP-I. It is assumed that this protein may sequester RA in the cytoplasm or even contribute to its catabolism in the mitochondria $[34,35]$. There is also evidence that retention of PK by CRABP-I interfere with its interaction with CRABP-II, thereby suppressing CRABPII-RAR-dependent signaling [36]. Finally, there is evidence that CRABP-I has no effect on RA effects at all, including on the transcriptional activity of RAR [12,37] and on the expression of retinoid responsive genes, although causes a decrease in intracellular RA concentration [38]. In addition, our own data indicate that CRABP-I can enhance tumorigenicity of transformed cells, regardless to its RA-binding ability [39]. In any case, It seems like most if not all the known functions of CRABP-I are attributed to its activity in the cytoplasm.

In this respect, recently published data on "non-canonical" activity of RA, in the mediating of which CRABP-I can participate, seems very interesting. Thus, it was shown, that RA can stimulate non genomic activation of the key signaling pathways such as MAPK-- и Akt-dependent cascades. Particularly, all-trans retinoic acid (atRA) promoted activation of the PI3k/ Akt pathway via transcription-independent mechanisms by translocation of RAR $\alpha$ to the plasma membrane and association of RAR $\alpha$ with Akt [40]. The same group also recently reported the transcription-independent mechanisms of Erk1/2 activation by atRA [41]. Importantly, CRABP-I can contribute to this non-canonical activity of the RA, what has been demonstrated in two studies. The authors have found that CRABP-I mediates the non-canonical, RAR- and membrane signal-independent activation of ERK1/2 by atRA in various cellular backgrounds [42]. Noteworthy, in this case CRABP-I-dependent activation of Erk1 /2 resulted in the stimulation of apoptosis and correspondingly, CRABP-I demonstrated anti-oncogenic activity [43]. In general, the functional significance of CRABP-I in carcinogenesis remains poorly understood, and the data on this issue are highly controversial - some testify to its tumor suppressing activity [44-48] while others indicate its association with cancer or with poor prognosis for cancer patients $[36,49]$.

The situation is further complicated by the fact that both CRABP homologs apparently have activities and target proteins independent from RA and its receptors. In particular, for CRABPII, the direct interaction with the members of Hu group of proteins has been showed recently [50]. These proteins are involved in post-transcriptional regulation of gene expression and mRNA stability. Interestingly, the protein-protein interaction of CRABPII with HuR markedly increases the affinity of HuR for certain target transcripts. CRABP-II thus enhances the stability and increases the expression levels of these transcripts including mRNAs for the certain proapoptotic genes, such as Apaf- 1 and Casp7 as well as for HuR itself. Therefore CRABP-II can realize anticarcinogenic activity using both mechanisms - RAR-dependent stimulation of transcription and up regulation of HuR [51]. However, in neuroblastoma cells CRABP-II apparently plays an opposite role, promoting cell malignancy. Notably, this activity is also associated with Hu proteins. In this case, CRABP-II through not well understood mechanism stimulates the production of $\mathrm{HuD}$ and $\mathrm{HuB}$ proteins, causing an increase in $\mathrm{MycN}$ expression, which is one of the main criteria for poor prognosis in neuroblastomas [52].

In glioblastomas (GBM), the accumulation of CRABP-II in the cytoplasm has been also determined as a factor of poor prognosis. The authors of this study showed, that CRABP-II accumulates in the cytoplasm of GBM cells, attenuating the transcriptional activity of RARs and thereby promoting tumor cells survival [31]. 


\section{Cancer Therapy \& Oncology International Journal}

These data are in good agreement with the results of CRABP proteins study in breast cancer cells, where it has been shown that nuclear but not cytoplasmic, CRABP-II was positively associated with patient survival, while cytoplasmic CRABP-I was associated with a poor prognosis. Moreover, the authors of this research propose that CRABP-I accumulation in the cytoplasm prevents RAR activation in the nucleus. Noteworthy, this is one of the very few articles where all three RC binding proteins CRABP-I, CRABP-II as well as FABP5) were studied simultaneously in the same cells. The authors found that CRABP-I negatively regulates CRABP-II expression and also suppress CRABP-II activity via CRABP-I-dependent sequestration of RA in cytoplasm and repression of RA-mediated nuclear translocation of CRABP-II [36]. Given that expression of genes encoding described above RA-binding proteins, in turn, are themselves controlled by RAR transcriptional factors, the possibility of their mutual regulation seems very similar to the truth.

\section{Conclusion}

Summing up, it should be noted that many aspects of the functional activity of the RA- binding proteins remain unexplained. For example, the role of CRABP-I in the nucleus remains completely unclear. The question of similar or (more likely) the opposite role of CRABP-I and CRABP-II homologs with respect to carrying out RC-dependent signaling is also left open. The same concerns their role in cancer pathogenesis in general. It is likely that these proteins could be at least partially responsible for the different effects of RA in different types of cancer, and also could contribute to the formation of the resistance to RA treatment. The only thing that seems obvious is the great importance of these proteins in carcinogenesis and the need for their further research. This should include the simultaneous study of all RA-binding proteins in the same cells, an analysis of their activity both in the cytoplasm and in the nucleus, and estimation of their effects on the canonical and non-transcriptional activity of RA.

\section{Acknowledgment:}

The study was supported by Russian Foundation for Basic Research, grant № 16-04-01559A.

\section{References}

1. Altucci L, Gronemeyer H (2001) The promise of retinoids to fight against cancer. Nat Rev Cancer 1(3): 181-193.

2. Soprano DR, Qin P, Soprano KJ (2004) Retinoic Acid Receptors And Cancers. Annu Rev Nutr 24(1): 201-221.

3. Bushue N, Wan YJ (2010) Retinoid pathway and cancer therapeutics. Adv Drug Deliv Rev 62(13): 1285-1298.

4. Connolly RM, Nguyen NK, Sukumar S (2013) Molecular pathways: current role and future directions of the retinoic acid pathway in cancer prevention and treatment. Clin Cancer Res 19(7): 1651-1659.

5. Garattini E, Gianni M, Terao M (2007) Retinoids as differentiating agents in oncology: a network of interactions with intracellular pathways as the basis for rational therapeutic combinations. Curr Pharm Des 13(13): 1375-1400.
6. Freemantle SJ, Spinella MJ, Dmitrovsky E (2003) Retinoids in cancer therapy and chemoprevention: promise meets resistance. Oncogene 22(47): 7305-7315.

7. Verma AK, Conrad EA, Boutwell RK (1982) Differential effects of retinoic acid and 7,8-benzoflavone on the induction of mouse skin tumors by the complete carcinogenesis process and by the initiationpromotion regimen. Cancer Res 42(9): 3519-3525.

8. Kang S, Duell EA, Fisher GJ, Datta SC, Wang ZQ et al. (1995) Application of retinol to human skin in vivo induces epidermal hyperplasia and cellular retinoid binding proteins characteristic of retinoic acid but without measurable retinoic acid levels or irritation. J Invest Dermatol 105(4): 549-556.

9. Schug TT, Berry DC, Shaw NS, Travis SN, Noy N (2007) Opposing effects of retinoic acid on cell growth result from alternate activation of two different nuclear receptors. Cell 129(4): 723-733.

10. Henion PD, Weston JA (1994) Retinoic acid selectively promotes the survival and proliferation of neurogenic precursors in cultured neural crest cell populations. Dev Biol 161(1): 243-250.

11. Rodriguez-Tebar A, Rohrer H (1991) Retinoic acid induces NGFdependent survival response and high-affinity NGF receptors in immature chick sympathetic neurons. Development 112(3): 813-820.

12. Dong D, Ruuska SE, Levinthal DJ, Noy N (1999) Distinct roles for cellular retinoic acid-binding proteins I and II in regulating signaling by retinoic acid. J Biol Chem 274(34): 23695-23698.

13. Tan NS, Shaw NS, Vinckenbosch N, Liu P, Yasmin R, et al. (2002) Selective cooperation between fatty acid binding proteins and peroxisome proliferator-activated receptors in regulating transcription. Mol Cell Biol 22(14): 5114-5127.

14. Sussman F, de Lera AR (2005) Ligand recognition by RAR and RXR receptors: binding and selectivity. J Med Chem 48(20): 6212-6219.

15. Berry DC, Noy N (2009) All-trans-retinoic acid represses obesity and insulin resistance by activating both peroxisome proliferationactivated receptor beta/delta and retinoic acid receptor. Mol Cell Biol 29(12): 3286-3296.

16. Schug TT, Berry DC, Toshkov IA, Cheng L, Nikitin AY, et al. (2008) Overcoming retinoic acid-resistance of mammary carcinomas by diverting retinoic acid from PPARbeta/delta to RAR. Proc Natl Acad Sci U S A 105(21): 7546-7551.

17. Donato LJ, Suh JH, Noy N (2007) Suppression of mammary carcinoma cell growth by retinoic acid: the cell cycle control gene Btg2 is a direct target for retinoic acid receptor signaling. Cancer Res 67(2): 609-615.

18. Afonja O, Raaka BM, Huang A, Das S, Zhao X, et al. (2002) RAR agonists stimulate SOX9 gene expression in breast cancer cell lines: evidence for a role in retinoid-mediated growth inhibition. Oncogene 21(51): 7850-7860.

19. Afonja O, Juste D, Das S, Matsuhashi S, Samuels HH (2004) Induction of PDCD4 tumor suppressor gene expression by RAR agonists, antiestrogen and HER-2/neu antagonist in breast cancer cells. Evidence for a role in apoptosis. Oncogene 23(49): 8135-8145.

20. Soprano DR, Qin P, Soprano KJ (2004) Retinoic acid receptors and cancers. Annu Rev Nutr 24: 201-221.

21. Noy N (2010) Between death and survival: retinoic acid in regulation of apoptosis. Annu. Rev. Nutr 30(1): 201-217.

22. Di-Poï N, Michalik L, Tan NS, Desvergne B, Wahli W (2003) The antiapoptotic role of PPARbeta contributes to efficient skin wound healing. J Steroid Biochem Mol Biol 85(2-5): 257-265.

23. Montagner A, Delgado MB, Tallichet-Blanc C, Chan JS, Sng MK, et al. (2014) Src is activated by the nuclear receptor peroxisome 


\section{Cancer Therapy \& Oncology International Journal}

proliferator-activated receptor $\beta / \delta$ in ultraviolet radiation-induced skin cancer. EMBO Mol Med 6(1): 80-98.

24. Di-Poï N, Tan NS, Michalik L, Wahli W, Desvergne B (2002) Antiapoptotic role of PPARbeta in keratinocytes via transcriptional control of the Akt1 signaling pathway. Mol Cell 10(4): 721-733.

25. Schug TT, Berry DC, Shaw NS (2007) Dual transcriptional activities underlie opposing effects of retinoic acid on cell survival. Cell 129(4): 723-733.

26. Jing Y, Waxman S, Mira-y-Lopez R (1997) The cellular retinoic acid binding protein II is a positive regulator of retinoic acid signaling in breast cancer cells. Cancer Res 57(9): 1668-1672.

27. Calmon MF, Rodrigues RV, Kaneto CM, Moura RP, Silva SD, et al. (2009) Epigenetic silencing of CRABP2 and MX1 in head and neck tumors. Neoplasia 11(12): 1329-1339.

28. Budhu AS, Noy N (2002) Direct channeling of retinoic acid between cellular retinoic acid-binding protein II and retinoic acid receptor sensitizes mammary carcinoma cells to retinoic acid-induced growth arrest Mol Cell Biol 22(8): 2632-2641.

29. Tsibris JCM, Segars J, Coppola D, Mane S, Wilbanks GD, et al. (2002) Insights from gene arrays on the development and growth regulation of uterine leiomyomata. Fertil Steril 78(1): 114-121.

30. Mallikarjuna K, Sundaram CS, Sharma Y, Perinkulam Ravi Deepa, Vikas Khetan, et al. (2010) Comparative proteomic analysis of differentially expressed proteins in primary retinoblastoma tumors. Proteomics Clin Appl 4(4): 449-463.

31. Liu RZ, Li S, Garcia E, glubrecht DD, Poon HY, Easaw, et al. (2016) Association between cytoplasmic CRABP2, altered retinoic acid signaling, and poor prognosis in glioblastoma. Glia 64(6): 963-976.

32. Gaub MP, Lutz Y, Ghyselinck NB, Scheuer I, Pfister V, et al. (1998) Nuclear detection of cellular retinoic acid binding proteins I and II with new antibodies. J Histochem Cytochem 46(10): 1103-1111.

33. Noy N (2000) Retinoid-binding proteins: mediators of retinoid action. Biochem J 348: 481-495.

34. Fiorella PD, Napoli JL (1991) Expression of cellular retinoic acid binding protein (CRABP) in Escherichia coli. Characterization and evidence that holo-CRABP is a substrate in retinoic acid metabolism. J. Biol Chem 266(25): 16572-16579.

35. Boylan JF, Gudas LJ (1992) The level of CRABP-I expression influences the amounts and types of all-trans-retinoic acid metabolites in F9 teratocarcinoma stem cells. J Biol Chem 267(30): 21486-21491.

36. Liu RZ, Garcia E, Glubrecht DD, Poon HY, Mackey JR, et al. (2015) CRABP1 is associated with a poor prognosis in breast cancer: adding to the complexity of breast cancer cell response to retinoic acid. Mol. Cancer 14(1): 129.

37. Venepally P, Reddy LG, Sani BP (1996) Analysis of the Effects of CRABP I Expression on the RA-Induced Transcription Mediated by Retinoid Receptors. Biochemistry 35(31): 9974-9982.

38. Chen AC, Yu K, Lane MA, Gudas LJ (2003) Homozygous deletion of the CRABPI gene in AB1 embryonic stem cells results in increased CRABPII gene expression and decreased intracellular retinoic acid concentration. Arch Biochem Biophys 411(2): 159-173.
39. Kainov Y, Favorskaya I, Delektorskaya V, , Chemeris G, Komelkov A, et al. (2014) CRABP1 provides high malignancy of transformed mesenchymal cells and contributes to the pathogenesis of mesenchymal and neuroendocrine tumors. Cell Cycle 13(10): 1530-1539.

40. García-Regalado A, Vargas M, García-Carrancá A, Aréchaga-Ocampo E, González-De la Rosa CH (2013) Activation of Akt pathway by transcription-independent mechanisms of retinoic acid promotes survival and invasion in lung cancer cells. Mol Cancer 12: 44.

41. Quintero Barceinas RS, García-Regalado A, Aréchaga-Ocampo, Nicolás Villegas-Sepúlveda, Claudia Haydée González-De la Rosa E (2015) All-Trans Retinoic Acid Induces Proliferation, Survival, and Migration in A549 Lung Cancer Cells by Activating the ERK Signaling Pathway through a Transcription-Independent Mechanism. Biomed Res Int 2015: 404368.

42. Persaud SD, Lin YW, Wu CY, Kagechika H, Wei LN (2013) Cellular retinoic acid binding protein I mediates rapid non-canonical activation of ERK1/2 by all-trans retinoic acid. Cell Signal 25(1): 19-25.

43. Persaud SD, Park SW, Ishigami-Yuasa M, Naoko Koyano-Nakagawa, Hiroyuki Kagechika, et al. (2016) All trans-retinoic acid analogs promote cancer cell apoptosis through non-genomic Crabp1 mediating ERK1/2 phosphorylation Sci Rep 6(1): 22396.

44. Lind GE, Kleivi K, Meling GI, Teixeira MR, Thiis-Evensen E, et al. (2006) ADAMTS1, CRABP1, and NR3C1 identified as epigenetically deregulated genes in colorectal tumorigenesis. Cell Oncol 28(5-6): 259-272.

45. Tanaka K, Imoto I, Inoue J, Kozaki K, Tsuda H, et al. (2007) Frequent methylation-associated silencing of a candidate tumor-suppressor, CRABP1, in esophageal squamous-cell carcinoma. Oncogene 26(44): 6456-6468.

46. Huang Y, de la Chapelle A, Pellegata NS (2003) Hypermethylation, but not LOH, is associated with the low expression of MT1G and CRABP1 in papillary thyroid carcinoma. Int J cancer 104(6): 735-744.

47. Hawthorn L, Stein L, Varma R, Wiseman S, Loree T, et al. (2004) TIMP1 and SERPIN-A overexpression and TFF3 and CRABP1 underexpression as biomarkers for papillary thyroid carcinoma. Head Neck 26(12): 1069-1083.

48. Miyake T, Ueda Y, Matsuzaki S, Miyatake T, Yoshino K, et al. (2011) CRABP1-reduced expression is associated with poorer prognosis in serous and clear cell ovarian adenocarcinoma. J Cancer Res Clin Oncol 137(4): 715-722.

49. Doldo E, Costanza G, Ferlosio A (2015) High expression of cellular retinol binding protein- 1 in lung adenocarcinoma is associated with poor prognosis. Genes Cancer 6(11-12): 490-502.

50. Vreeland AC, Yu S, Levi L, de Barros Rossetto D, Noy N (2014) Transcript Stabilization by the RNA-Binding Protein HuR Is Regulated by Cellular Retinoic Acid-Binding Protein 2. Mol Cell Biol 34(12): 2135-2146.

51.Vreeland AC, Levi L, Zhang W, Berry DC, Noy N (2014) Cellular retinoic acid-binding protein 2 inhibits tumor growth by two distinct mechanisms. J Biol Chem 289(49): 34065-34073.

52. Gupta A, Williams BRG, Hanash SM, Rawwas J (2006) Cellular retinoic acid-binding protein II is a direct transcriptional target of $\mathrm{MycN}$ in neuroblastoma. Cancer Res 66(16): 8100-8108. 


\section{Your next submission with Juniper Publishers will reach you the below assets}

- Quality Editorial service

- Swift Peer Review

- Reprints availability

- E-prints Service

- Manuscript Podcast for convenient understanding

- Global attainment for your research

- Manuscript accessibility in different formats

( Pdf, E-pub, Full Text, Audio)

- Unceasing customer service

Track the below URL for one-step submission https://juniperpublishers.com/online-submission.php 